\title{
Artificial Neural Network Implementation for Maximum Power Point Tracking of Optimized Solar Panel
}

\author{
Lalam S. Sindhura \\ Indian Institute of Technology (Banaras Hindu \\ University) \\ Student IDD
}

\author{
Kalpana Chaudhary \\ Indian Institute of Technology (Banaras Hindu \\ University) \\ Assistant Professor
}

\begin{abstract}
In this paper, maximum power point tracking of solar panel using artificial neural network control is developed and simulated in Mat lab. The Solar panel is modeled using conventional five parameter model and adjusted according to the manufacturer's datasheet values by calculating its internal resistance using an iterative process, Newton-Raphson method. A simple DC-DC Boost converter is used to transfer the maximum power to the load which is achieved by using a control strategy that changes the duty cycle of this converter accordingly. Artificial Neural Network is used to generate the reference values, according to the changing atmospheric conditions, that are required for the control strategy. Training of the neural network is done using the Mat lab tool box using feed forward back propagation training algorithm and mean square error algorithm is used for calculating the error. The proposed model is compared with conventional Perturb and Observe technique and shown that method using ANN gives better results.
\end{abstract}

\section{Keywords}

Artificial Neural Network (ANN), solar panel, Maximum Power Point Tracking (MPPT)

\section{INTRODUCTION}

In the present scenario of world's increased energy utilization and decreased conventional resources, use of renewable energy resources is an efficient and convincing consideration. The rapid growth in PV cells technology made the installation and utilization of solar power very easy. The PV systems are non linear power sources with non linear internal resistance. To operate these PV systems effectively, they must be operated at their maximum power. This maximum power transfer happens if the internal resistance of the system is equal to the load resistance. This can be achieved by inserting a DC-DC converter in between the load and the PV system.

Also, the efficiency of conversion of energy in solar panel is very low. So to overcome this problem, the solar panel modeling must be optimized. This is done by calculating the optimized values of 5 parameter model given by Gow and Manning [1].

The maximum power of the solar panel depends on the atmospheric conditions like ambient temperature and irradiation levels. So this maximum power has to be tracked to operate solar panel at MPP (maximum power point) at varying conditions. There are many techniques in the literature to achieve this [2], perturb and observe being most common one among them [3]. There are also other techniques like incremental conductance [4]. Also different control strategies for the chopper have been proposed in the past like conventional PID control and fuzzy logic control [5]. Many
MPPT techniques considering the rapidly changing atmospheric conditions are also there in literature [6].

Recent developments in the neural networks increased its utilization in a wide range of applications. In this paper, neural network is used to track the MPP at varying atmospheric conditions and a comparison between the MPPT techniques PO and ANN is made. Simulations for the same are carried out in Mat lab/ Simulink.

\section{Modeling of Solar Panel}

Solar cell is the device which absorbs the solar energy and converts it in to electrical energy. These days, silicon PN junction cell which has an approximate efficiency of $17 \%$ is the most commonly used cell type. When solar radiation falls on this cell, photon creates an electron-hole pair. Typically the output of this solar cell is very low, so many of these cells are connected is series or parallel. No. of cells connected in series increase the voltage, while the no. of cells connected in parallel increase the current. The circuit for the 5 parameter model given in [1] is shown in Figure 1.

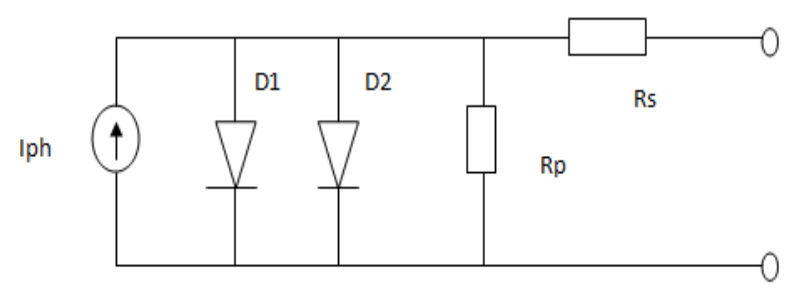

Figure 1: Model of Solar Panel

The PV panel current is given by Eqn.1. This is known as double exponential model. It is suggested that cells constructed from amorphous silicon using thick-film deposition techniques, do not exhibit a sharp knee in the curve as the crystalline types do. In such cases Eqn.2 provides a better fit. This equation is obtained by second saturation current $\mathrm{I}_{\mathrm{s} 2}$ to zero. This model offers a good compromise between simplicity and accuracy.

$$
\begin{aligned}
& I_{p v}=I_{p h}-I_{s 1}\left[e^{\left\{\frac{V_{p v}+I_{p v} R_{s}}{V t}\right\}}-1\right]-I_{s 2}\left[e^{\left\{\frac{V_{p v}+I_{p v} R_{s}}{V t}\right\}}-1\right]-\frac{V_{p v}+I_{p v} R_{s}}{R_{p}} \\
& I_{p v}=I_{p h}-I_{s}\left[e^{\left\{\frac{V_{p v}+I_{p v} R_{s}}{V t}\right\}}-1\right]-\frac{V_{p v}+I_{p v} R_{s}}{R_{p}}
\end{aligned}
$$

Where,

Ipv is the PV panel current;

$\mathrm{Vpv}$ is the PV panel voltage; 
Iph is the photo current given by Eqn. 3,

$$
\mathrm{I}_{\mathrm{ph}}=\left\{\mathrm{I}_{\mathrm{ph}, \mathrm{ref}}\left[1+\mathrm{K}_{\mathrm{I}}\left(\mathrm{T}-\mathrm{T}_{\mathrm{ref}}\right)\right]\right\} \frac{\mathrm{G}}{\mathrm{G}_{\mathrm{ref}}}
$$

Here, $\mathrm{KI}$ is the current temperature coefficient;

$\mathrm{T}$ is cells working temperature;

Tref is reference temperature;

$\mathrm{G}$ is irradiation;

Gref is irradiation at reference conditions;

$\mathrm{Vt}$ is the thermal voltage given by Eqn. 6,

$\mathrm{V}_{\mathrm{t}}=\frac{n_{r e f} k T_{r e f}}{q} \frac{\mathrm{T}}{\mathrm{T}_{\text {ref }}}$

Where, $\mathrm{k}$ is Boltzmann constant;

$\mathrm{q}$ is electron charge;

$\mathrm{n}$ is ideality constant;

Is 1 and Is 2 are cell saturation currents;

Rs and Rp are the series and parallel resistances respectively.

Modeling of the above equation requires some parameters which are not available in the manufactures datasheet like series resistance, shunt resistance, photo generated current, reverse saturation current, ideality factor e.t.c. so these values are calculated to fit the P-V /I-V curve of the solar panel evaluated at 3 remarkable points, i.e., at open circuit voltage (Voc), short circuit current (Isc), and at maximum power point at reference conditions (Pmp). To achieve this, an iterative process is adapted to calculate the $\mathrm{Rs}$ and $\mathrm{Rp}$ values so as to get remaining quantities.

In normal devices the series resistance is of a lower value and shunt resistance is high, so an assumption given in Eqn.5 can be considered. But taking Rs and Rp into account gives better result [7], so Eqn.6 is considered in this work.

$\mathrm{I}_{\mathrm{ph}, \text { ref }}=\mathrm{I}_{\mathrm{sc}, \text { ref }}$

$I_{p h, \text { ref }}=\frac{R_{p}+R_{s}}{R_{p}} I_{s c, \text { ref }}$

The diode saturation current Is is given by Eqn.7.

$\mathrm{I}_{\mathrm{s}}=\mathrm{I}_{\mathrm{s}, \mathrm{ref}}\left[\frac{\mathrm{T}_{r e f}}{\mathrm{~T}}\right]^{3} \exp \left\{\frac{\mathrm{qE}_{\mathrm{g}}}{\mathrm{nk}}\left(\frac{1}{\mathrm{~T}_{r e f}}-\frac{1}{\mathrm{~T}}\right)\right\}$

Where,

$I_{s, \text { ref }}=\frac{I_{\text {sc,ref }}}{e^{\left\{\frac{v_{\text {oc }}}{v_{t, \text { ref }}}\right\}}-1}$

By including the current and voltage coefficients in the Eqn.7 a better approach to reduce the model error in the vicinities of open circuit voltage is achieved, thereby in the other regions of the curve. Now, Is is given by Eqn.9.

$$
I_{s}=\frac{I_{s c, r e f}+K_{I}\left(T-T_{\text {ref }}\right)}{e^{\left\{\frac{v_{o c}+K_{V}\left(T-T_{\text {ref }}\right)}{V_{t}}\right\}}-1}
$$

Where, $\mathrm{Kv}$ is voltage temperature coefficient.

And the diode ideality constant is chosen arbitrarily, usually, between 1 and 1.5 .

To fit the curve, the condition Pmax, m=Pmax, e is checked after every iteration.

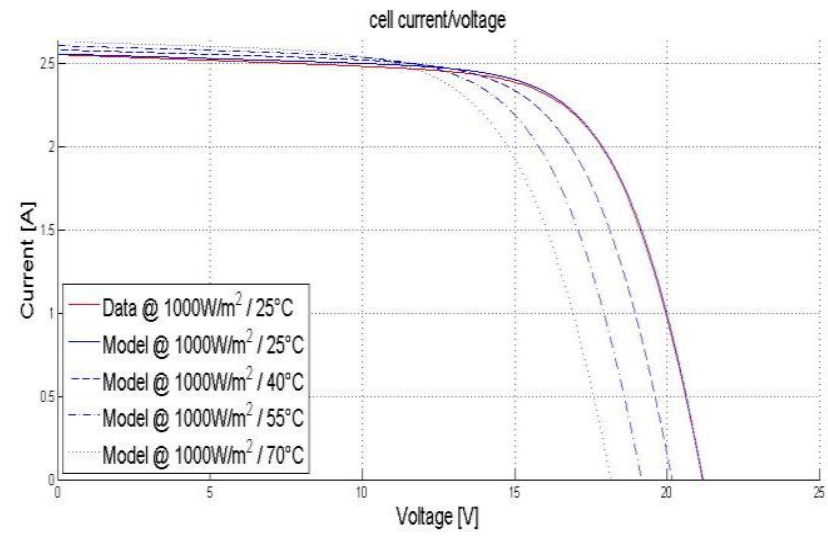

Figure 2: I-V Curves with Varying Temperature powerNoltage

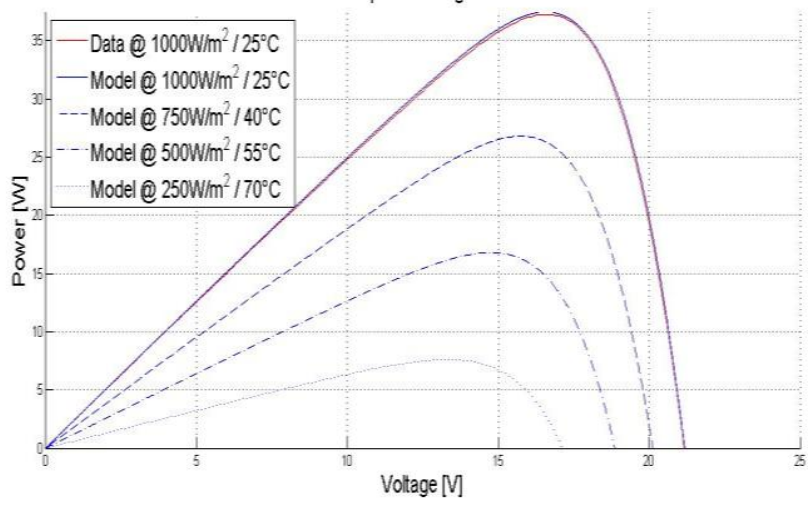

Figure 3: P-V Curves with Varying Temperature and Power

The I-V and P-V curves are as shown in Figure 2 and Figure 3 respectively. This has been modeled for the solar panel by solkar, which has an open circuit voltage Voc of $21.24 \mathrm{~V}$, short circuit current Isc being $2.55 \mathrm{~A}$. Vmp, Imp, and Pmp are $16.56 \mathrm{~V}, 2.25 \mathrm{~A}$ and $37.08 \mathrm{~W}$ respectively. Also, the curve fitting is shown. These parameters can be used in designing any model of solar panels, by connecting this current calculated to a constant current source as shown in Figure 1.

\section{DESIGN OF DC-DC CONVERTER}

The Boost converter can be modeled by the equations relating input and output voltage/current as follows [8]:

$$
\begin{aligned}
V_{\text {out }} & =\frac{D V_{\text {in }}}{1-D} \\
I_{\text {out }} & =\frac{(1-D) I_{\text {in }}}{D}
\end{aligned}
$$


The inductor $(\mathrm{L})$ and capacitor $(\mathrm{C})$ values are calculated by using the Eqn.12 and Eqn.13 respectively.

$$
\begin{aligned}
& L=\frac{\left(V_{\text {out }}-V_{\text {in }}\right) V_{\text {in }}}{f \Delta I V_{\text {out }}} \\
& C=\frac{\left(V_{\text {out }}-V_{\text {in }}\right) I_{\text {out }}}{f \Delta V V_{\text {out }}}
\end{aligned}
$$

Where, $\mathrm{D}$ is the duty cycle;

Vin and Vout are the input and output voltages respectively;

$\mathrm{f}$ is the switching frequency;

$\Delta \mathrm{I}$ and $\Delta \mathrm{V}$ are current and voltage ripples respectively.

From the above equations the values of $\mathrm{L}$ and $\mathrm{C}$ are calculated and inductor value is taken as $160 \mathrm{u} \mathrm{H}$ and capacitor value is taken as $330 \mathrm{u} \mathrm{F}$.

\section{PERTURB AND OBSERVE METHOD}

The most common and simple technique to track maximum power of solar panel is perturb and observe ( $\mathrm{P}$ and $\mathrm{O}$ ) method. In this method, power output of the array is monitored every cycle and is compared to its Value before each Perturbation is made. If a change (either positive or negative) in the duty cycle of the DC-DC converter causes output power to increase, the duty cycle is changed in the same direction. If it causes the output power to decrease, then it is reversed to the opposite direction [9]. P and O method is simulated in Mat lab Simulink as described in the flow chart shown in Figure 4.

\section{Artificial Neural Network}

A neuron is a cell made up of a cellular body and a core in which the cellular body ramifies to form the dendrites. Dendrites transfer the information between the neuron and the soma, body of the neuron. There is an intercellular space between the axon of the related neuron and dendrites of the efferent neuron. The junction between two neurons works like a valve controlling the rate of flow of information, and is called as synapse. It is necessary to parameterize all these synapses to achieve a goal. The neural network works according to the Eqn.14.

$a_{i=} \sum_{j=1}^{N} W_{i j} X_{j}$

Where, ai is output of the neural network at node $\mathrm{i}$;

Wij is the weight between the nodes $i$ and $j$;

$\mathrm{Xj}$ are the states variables evaluated by activation functions.

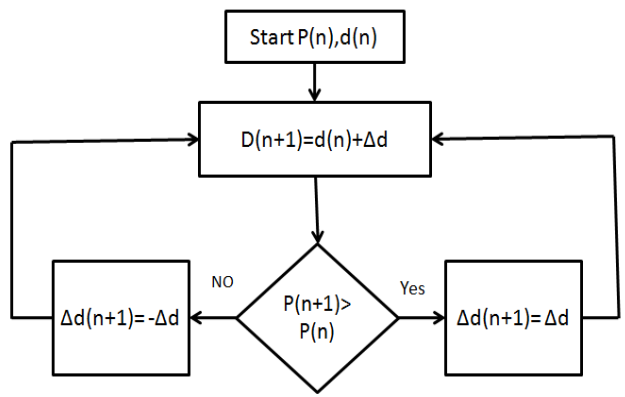

Figure 4: Flow Chart for $P$ and $O$ Method

\subsection{Data Acquisition for Training}

In the proposed model, measurement voltage and current of PV panel are being used as the input of ANN, the output is the voltage at MPP and power corresponding. The training data is obtained by simulating the PV array in Mat lab/Simulink using the parameters that were supplied by manufacturer. The current, voltage and power at MPP for a range of irradiance and ambient temperature conditions are recorded which are then used as the training data for ANN [10]. Then, the atmospheric conditions recorded are used as the input data and corresponding MPP values are used as the output data for training the ANN. The neural network is obtained by training in Mat lab/Simulink with trainlm function using Levenberg Marquardt algorithm [11]. Due to some reasons like variation of the parameters of solar panel along with time and consideration of a tolerant error, the reference voltage that is generated is not the exactly optimal voltage but it is near to the MPP. So a reference point which is closer to the MPP is achieved by this.

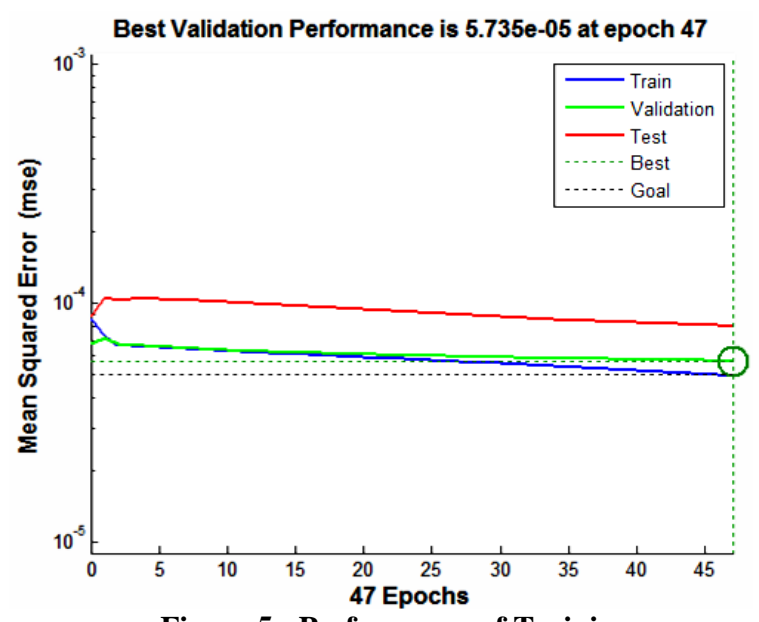

Figure 5: Performance of Training

\subsection{Training of Neural Networks}

Feed forward neural network is selected having 3 hidden layers, obtained by trial and error process. Tansig transfer function is used for hidden layers and by using back propagation method the network is trained using the data obtained.

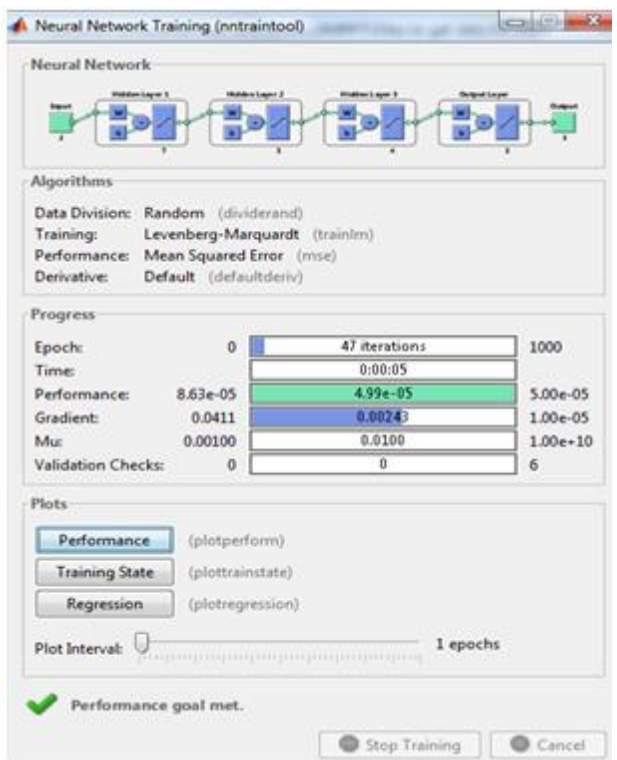

Figure 6: Training of Neural Network 
During the training process the error calculation is done by algorithm of mean square error method. A goal of $5 e-5$ is set with a value of 0.001 for mu and 1e-5 for gradient. Training is stopped when this goal is reached.

The plot in Figure 5 shows the performance and training of the network is shown in Figure 6.

\section{MODELING AND SIMULATION OF PV SYSTEM WITH MPPT}

As described in the previous sections the solar panel and the converter are developed and connected to the load. A solar panel consisting of 36 cells is considered in the present work. The solar panel is characterised by the Eqns.1-5 having atmospheric temperature and solar irradiation as the inputs.

The DC-DC boost converter is modelled based on the Eqns. 10-13. For the purpose of MPPT, either ANN or P and O can be used. Here in this paper both techniques are modelled and validated. A resistive load is considered in the present work.
The block diagram of SPV system used in this paper is shown in the Figure 7. And the circuit for the system developed is shown in Figure 8.

The same circuit is implemented using $\mathrm{P}$ and $\mathrm{O}$ technique.

\section{DISCUSSION OF RESULTS}

In this paper two MPPT methods have been analyzed, developed and simulated using mat lab/Simulink. Paper comprises the modeling of solar panel and the results are validated and compared with the manufacturer's datasheet values. Also design of Boost converter is done. The ANN tracker is designed and offline training is done and tested. A program to generate training data is written and with the help of that data for offline training of the ANN is generated for several sets of input variations. Converter's duty cycle control is used to transfer maximum power to the load. Duty cycle is modulated by comparing load voltage with the output of ANN. Also this MPPT technique is compared with the P and $\mathrm{O}$ technique which is also simulated using Mat lab/Simulink.

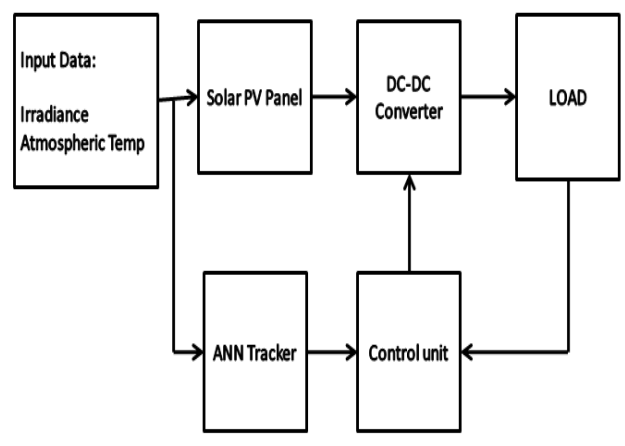

Figure7: Block Diagram of the PV System with MPPT

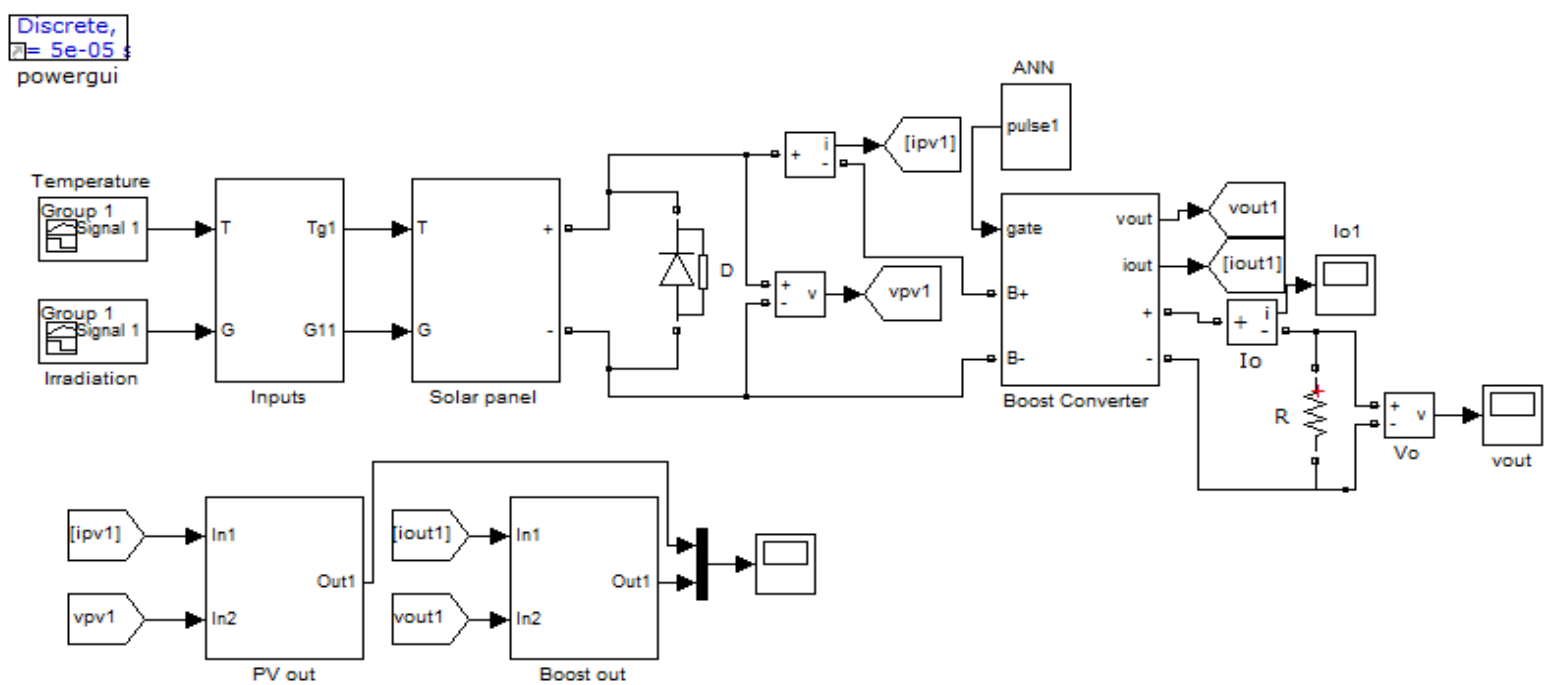

Figure 8: Circuit Diagram Simulated in MATLAB

The power output of the system with varying inputs is shown for ANN in the Figure 11. The input conditions of radiation and temperature are shown in the Figure 9 and Figure 10.
Figure12 illustrates the comparison of the settling times of the two methods used at four different atmospheric conditions. 


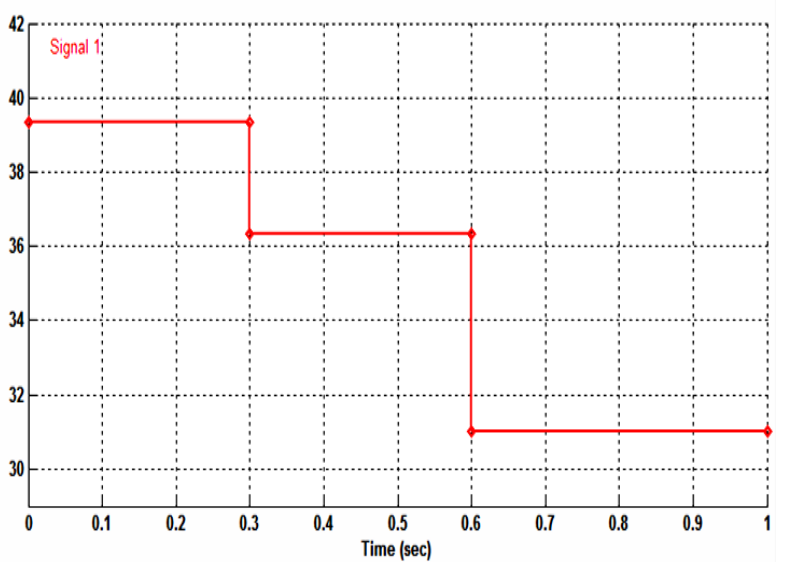

Figure 9: Temperature Variation

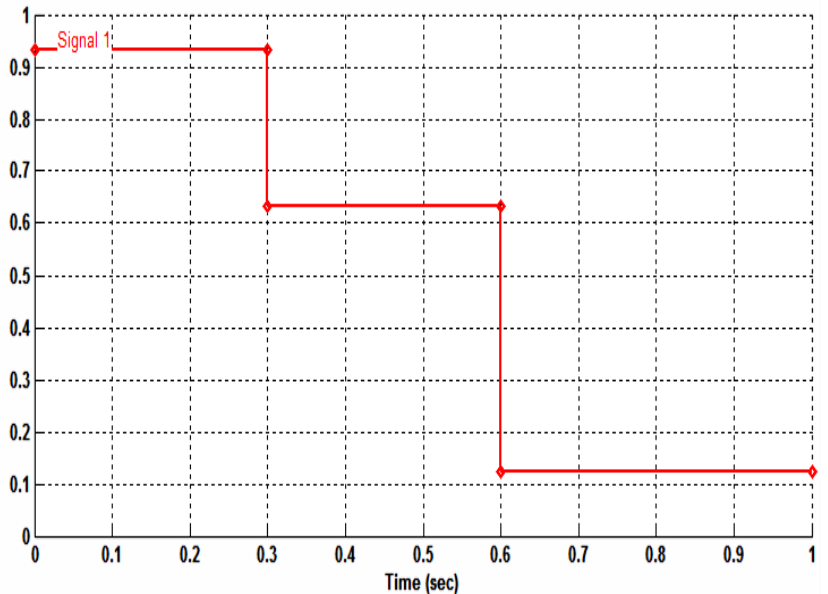

Figure 10: Waveform of Irradiation given as Input to the System

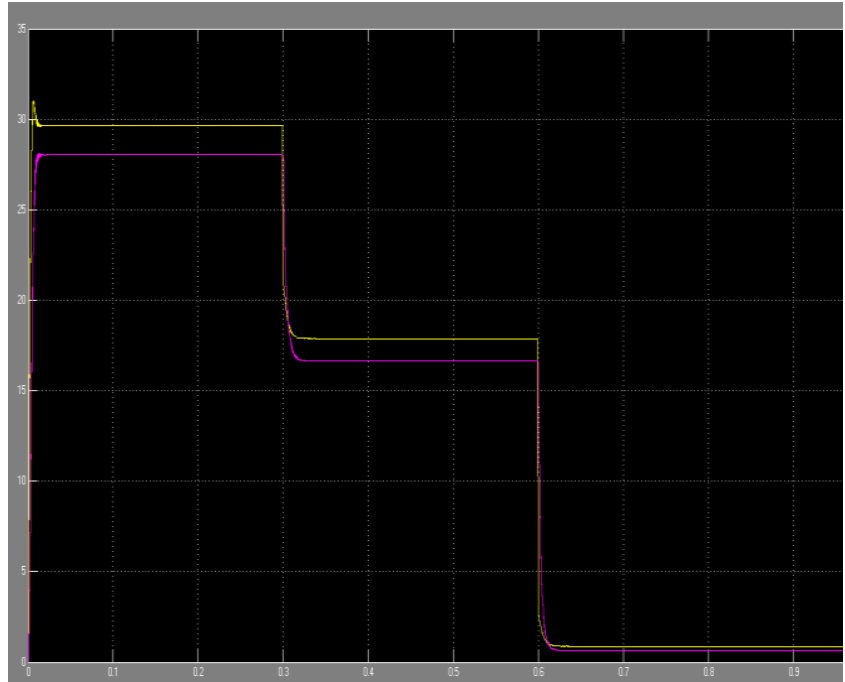

Figure 11: Output Power and Input Power by Using ANN MPPT

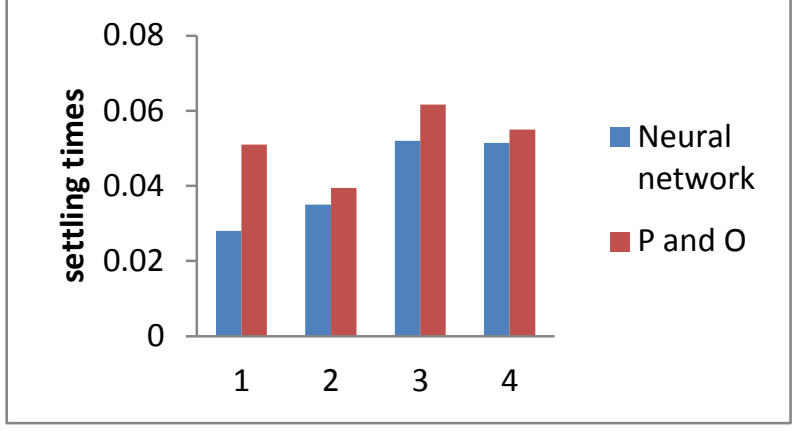

Figure 12: Settling Times of the Two Methods Used

\section{CONCLUSION}

A method for optimal use of solar energy generated has been developed and modelled. The advanced technology of ANN is used to predict the MPP conditions considering the variations in input levels of solar irradiation and temperature.ANN training is successfully done to achieve a goal of 5e-5. This is done by using the training data generated trough simulating the solar panel. MPPT techniques $\mathrm{P}$ and $\mathrm{O}$ and ANN are demonstrated, developed and validated. The results for the same are compared. The MPPT done using ANN has shown better result than the conventional PO controller.

\section{REFERENCES}

[1] J.A. Gow and C. Manning, "Development of a photovoltaic array model for use in power electronics simulation studies," in proc. IEE Electric power applications, vol 146, issue 2, pp.193-200, March 1999.

[2] Esram, T.; Chapman, P.L., "Comparison of Photovoltaic Array Maximum Power Point Tracking Techniques," Energy Conversion, IEEE Transactions on , vol.22, no.2, pp.439,449, June 2007.

[3] Weidong Xiao; Dunford, W.G.;, "A modified adaptive hill climbing MPPT method for photovoltaic power systems," 35th IEEE Annual Power Electronics Specialists Conference. PESC 04. vol.3, no., pp. 19571963 Vol.3, 20-25 June 2004.

[4] Strache, S.; Mueller, J.H.; Platz, D.; Wunderlich, R.; Heinen, S., "Maximum power point tracker for small number of solar cells connected in series," IECON 2012 38th Annual Conference on IEEE Industrial Electronics Society, vol., no., pp.5732,5737, 25-28 Oct. 2012.

[5] Sofai. Lalouni, Djamila. Rekioua, "Modeling and Simulation of Photovoltaic System, using Fuzzy Logic Controller", in IEEE International Conference on Developments in Systems Engineering, 2009.

[6] Tae-Yeop Kim; Ho-Gyun Ahn; Seung Kyu Park; YounKyun Lee, "A novel maximum power point tracking control for photovoltaic power system under rapidly changing solar radiation," Industrial Electronics, 2001. Proceedings. ISIE 2001. IEEE International Symposium on , vol.2, no., pp.1011,1014 vol.2, 2001.

[7] M. G. Villalva, et al.,"Comprehensive Approach to Modeling and Simulation of Photovoltaic Arrays," IEEE Transactions on Power Electronics, vol. 24, pp. 11981208,2009 
[8] N. Mohan, Tore M. Undeland, William P. Robbins, Power Electronics Converters: Application and Design, John Wiley \& Sons (Asia) Pvt. Ltd, 2004.

[9] Femia, N.; Petrone, G.; Spagnuolo, G.; Vitelli, M.; "Optimization of perturb and observe maximum power point tracking method," IEEE Transactions on Power Electronics, vol.20, no.4, pp. 963- 973, July 2005

[10] Ramaprabha, R.; Mathur, B.L.; Sharanya, M., "Solar array modeling and simulation of MPPT using neural network," Control, Automation, Communication and Energy Conservation, 2009. INCACEC 2009. 2009 International Conference on, vol., no., pp.1, 5, 4-6 June 2009.

[11] Anil K et al. "Simulation model of ANN based maximum power point tracking controller for solar PV system." Solar Energy Materials and Solar Cells 95.2 (2011), pp. 773-778. 